\title{
Pituitary metastases from the oncocytic variant of follicular thyroid carcinoma: a case report and diagnostic dilemmas
}

\author{
Ewa Matyja ${ }^{1,2}$, Grzegorz Zieliński ${ }^{3}$, Przemysław Witek $^{4}$, Grzegorz Kamiński ${ }^{4}$, Wiesława Grajkowska ${ }^{2,5}$, \\ Maria Maksymowicz ${ }^{6}$ \\ ${ }^{1}$ Department of Experimental and Clinical Neuropathology, M. Mossakowski Medical Research Centre, Polish Academy of Sciences, \\ ${ }^{2}$ Department of Neurosurgery, M. Sklodowska-Curie Memorial Cancer Centre and Institute of Oncology, ${ }^{3}$ Department of Neurosurgery, \\ Military Institute of Medicine, ${ }^{4}$ Department of Endocrinology and Radioisotope Therapy, Military Institute of Medicine, ${ }^{5}$ Department \\ of Pathology, The Children's Memorial Health Institute, ${ }^{6}$ Department of Pathology, M. Sklodowska-Curie Memorial Cancer Centre and \\ Institute of Oncology, Warsaw, Poland
}

\begin{abstract}
Metastases to the pituitary gland and sella turcica are uncommon. The distinction between primary and secondary metastatic pituitary tumours is challenging as carcinomas from distant sites might closely resemble, both clinically and histopathologically, non-functional adenomas or primary pituitary carcinomas.

Among metastases to pituitary gland ones from thyroid carcinoma are extremely rare. We present a unique case of a 53-year-old male patient with a past history of thyroid carcinoma who underwent repeated surgeries over a period of 7 years for a sellar-parasellar mass with paranasal sinus involvement. Morphologically, the tumour was composed of solid sheaths of monomorphic cells exhibiting oncocytic features. In electron microscope images, the cytoplasm of tumour cells was filled with numerous mitochondria. The tumour was negative for pituitary hormones but exhibited immunoreactivity for cytokeratin AE1/AE3, thyroglobulin and thyroid transcription factor 1 (TTF-1). Based on the clinical data and immunophenotypic profile, the tumour was finally diagnosed as an oncocytic variant of follicular thyroid carcinoma. To our knowledge, this is probably the first report of such peculiar histopathological variant of follicular thyroid carcinoma metastasizing to the pituitary gland. The diagnostic dilemmas considering oncocytic features of the presented case are discussed.
\end{abstract}

Key words: pituitary tumour, sellar metastases, oncocytoma, follicular thyroid carcinoma.

\section{Introduction}

Metastases to the pituitary gland and sella turcica are relatively rare. The first description of metastatic melanoma was made by Ludwig Benjamin in 1857 [6]. Most often the malignant metastatic pituitary tumours originate from the lung and breast, less commonly from the kidney, gastrointestinal tract, liver or prostate $[1,8,11,16,18,23,26,29,32,34]$. Pituitary metastases from thyroid carcinoma are extremely rare [4]. The differential diagnosis of pituitary metastases might be challenging as some carcinomas from distant sites closely resemble, both clinically and his- 
topathologically, primary non-functional adenomas or pituitary carcinomas $[11,28]$.

We present a case of a 53-year-old male patient who underwent repeated surgeries over a period of 7 years for a sellar-parasellar mass with paranasal sinus lesions, which was initially diagnosed as non-functioning pituitary adenoma. Ancillary immunohistochemical study made it possible to establish the final correct diagnosis of an oncocytic variant of follicular thyroid carcinoma. To our knowledge, this is probably the first report of thyroid carcinoma with oncocytic features metastasizing to the pituitary gland.

\section{Case report}

A 53-year-old male patient was admitted to the Department of Neurosurgery in April 2005 with symptoms of headaches, blurred vision and progressive diplopia. A neurological examination revealed decreased visual acuity in both eyes and mild hemiparesis of the right sixth cranial nerve with intact function of other cranial nerves. A funduscopic examination showed no signs of optic nerve atrophy. The patient did not present any somatic symptoms of hypercortisolemia or acromegaly. Magnetic resonance imaging (MRI) of the sellar-suprasellar region (coronal and sagittal T1-weighted with Gd-DTPA administration) demonstrated the large, solid, homogenous mass $(28 \times 25 \times 25 \mathrm{~mm})$ destructing the floor and clive, and
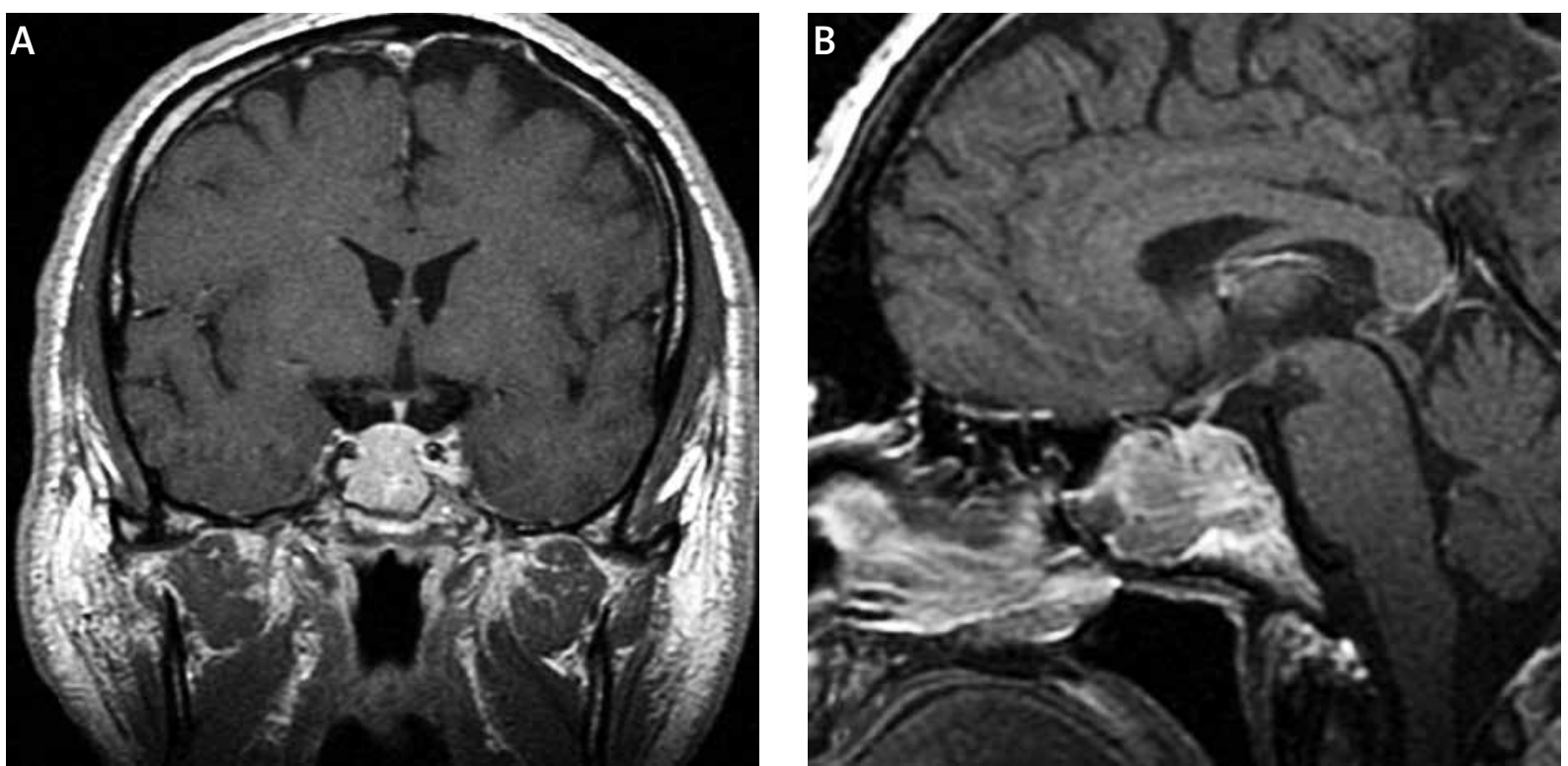

Fig. 1. Coronal (A) and sagittal (B) T1-weighted MRI exhibiting large, solid, homogenous sellar-parasellar mass destructing the floor and clive. 
(PTH) $(67.2 \mu \mathrm{g} / \mathrm{ml})$ and correct serum calcium levels allow us to exclude hyperparathyroidism, typical of MEN-1.

The patient underwent removal of the pituitary tumour by transsphenoidal surgery (TSS). The destruction of the sellar floor and invasion of the skull base was confirmed. The tumour was removed from the sella and sphenoid sinus except the part infiltrating the right cavernous sinus. The postoperative period was uneventful. There was no diabetes insipidus or hyponatremia. The replacement therapy with hydrocortisone was initiated. The postoperative hormone assessment performed six weeks after TSS revealed the normal range of GH and IGF-I level. Morning serum cortisol level was $10.5 \mu \mathrm{g} / \mathrm{dl}$ and its circadian rhythm was normal. The plasma ACTH was $39 \mathrm{pg} / \mathrm{ml}$. Therefore, after confirming the normal function of pituitary-adrenal axis, the hydrocortisone replacement therapy was withdrawn. The serum levels of $\mathrm{FSH}$, $\mathrm{LH}$ and $\mathrm{PRL}$ were within normal ranges $(4.7 \mathrm{mIU} / \mathrm{l}$; $2.6 \mathrm{mIU} / \mathrm{l} ; 16.2 \mathrm{ng} / \mathrm{ml}$, respectively).

The postoperative MRI confirmed a cavernous sinus infiltration by the remaining part of the tumour. The complementary radiotherapy was administered in a total dose of radiation of 5040 cGy within 36 days. The MRI of the sellar region, carried out six months after radiotherapy, showed no remnants of the tumour and the endocrine evaluation confirmed the normal pituitary function.

In 2008, three years after the TSS, the patient began to complain of nose swelling, nasal congestion, hyposmia and epistaxis. The laryngological examination revealed a tumour with a diameter of 12 $\times 14 \times 12 \mathrm{~mm}$ in the right nasal cavity. The tumour was removed and the patient was reoperated several times due to tumour re-growth in 2009, 2010, 2011 and 2012. The patient remains under constant control of neurosurgical, laryngological and endocrinological outpatient services and his general state is stable.

\section{Material and methods}

The specimens from two neurosurgeries were examined histopathologically, immunohistochemically and ultrastructurally. The tissue was fixed in $10 \%$ formalin, embedded in paraffin and routinely stained with hematoxylin and eosin (H\&E). Immunohistochemical staining was performed on paraffin-embedded specimens according to the labelled
EnVision Flex Visualization System (Dako, K8000) with $\mathrm{DAB}$ as chromogen, using antibodies against anterior pituitary hormones: PRL (dilution 1 : 200), $\mathrm{GH}$ (dilution $1: 500$ ), ACTH (dilution $1: 500$ ), $\beta$-TSH (dilution 1 : 500), $\beta$-FSH (dilution 1 : 500), $\beta$-LH (dilution $1: 500$ ) - all antibodies from LAB VISION and the glycoprotein $\alpha$-subunit (dilution 1 : 100, Novocastra). Ki-67 labelling index (MIB-1, dilution 1 : 100) was established. Moreover, antibodies against cytokeratins (AE1/AE3), thyroglobulin, S-100 and TTF1 (all antibodies from Dako) were used.

For electron microscopy, the small pieces of tissue were fixed in $2.5 \%$ glutaraldehyde, postfixed in $1 \%$ osmium tetroxide, dehydrated in graded alcohols and embedded in Epon 812. Ultrathin sections were counterstained with uranyl acetate and lead citrate and examined in a Philips CM 120 BioTWIN electron microscope.

\section{Results \\ Histopathological findings}

The morphology of neoplastic tissue was similar in material from both neurosurgeries performed in 2005 and 2011. The sellar tumour was composed of solid sheets containing large monomorphous cells of polygonal or square shape (Fig. 2A). These cells exhibited abundant, slightly granular, eosinophilic cytoplasm and a round nucleus with coarse chromatin and a centrally placed, relatively prominent nucleolus (Fig. 2B). Mitoses were rarely encountered and necrosis was absent. The MIB-1 labelling index was above $10 \%$ with a focal increase in proliferation activity up to $20 \%$ (Figs. 2C, D). The neoplastic cells were immunonegative for anterior pituitary hormones (PRL, GH, TSH, ACTH, FSH, LH, glycoprotein $\alpha$-subunit) and negative for chromogranin $A$ and synaptophysin (Fig. 3A).

In electron microscope images, the tumour was composed of poorly differentiated cells with oncocytic features. The cytoplasm of neoplastic cells was fulfilled by numerous mitochondria (Fig. 4). Their shape varied from round to oval and sometimes exhibited swollen matrix with flattened cristae (Fig. 5). Round to oval nuclei displayed scattered chromatin and a prominent, dark nucleolus. There was no evidence of secretory granules.

Based on morphology, immunohistochemistry and ultrastructure, the tumour was initially diagnosed as atypical, oncocytic pituitary adenoma of 

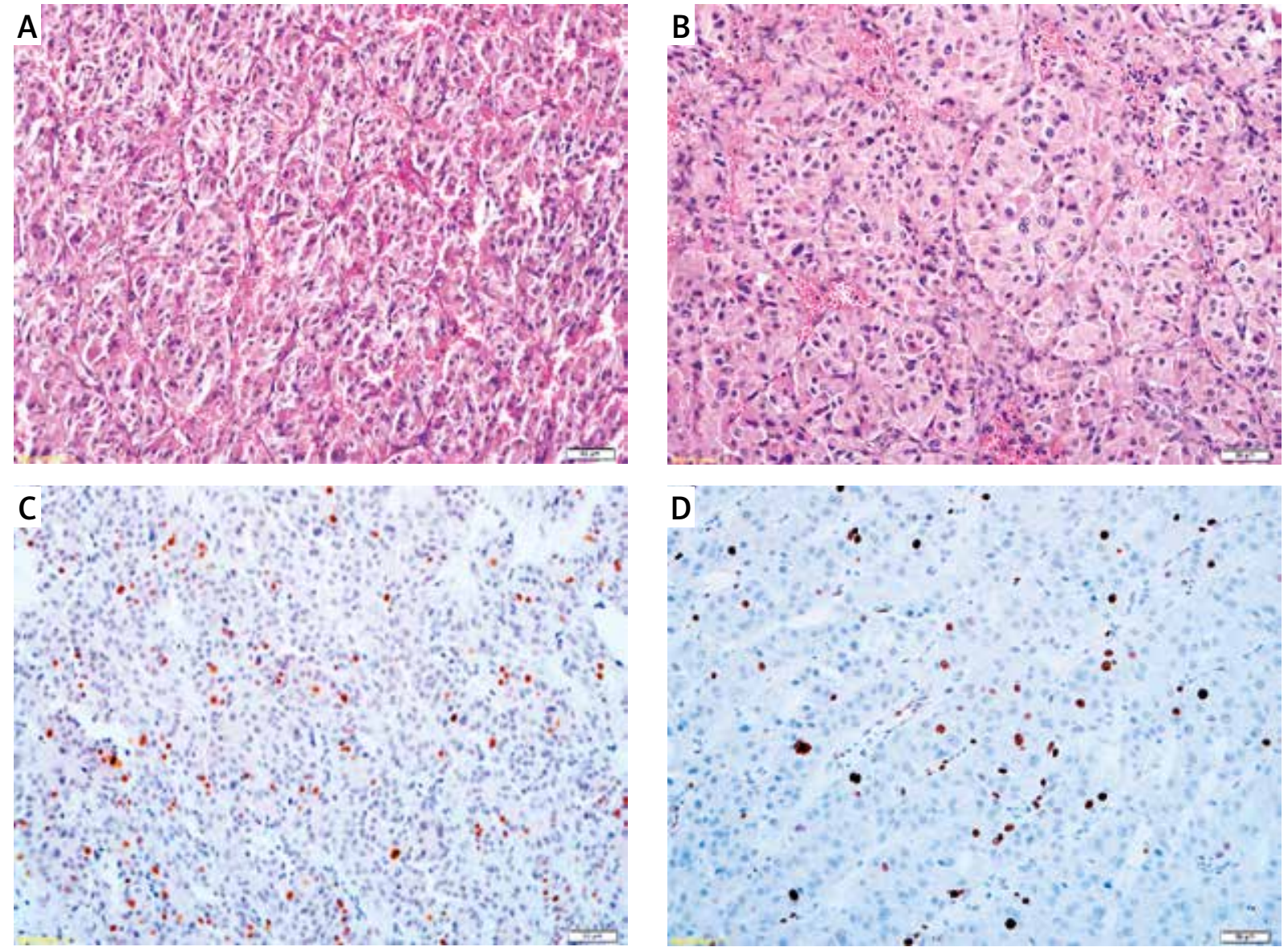

Fig. 2. Histopathology of pituitary tumour. The solid sheets of tumour cells with large monomorphous cells of polygonal or square shape (A - surgery 2005). The cells exhibiting abundant, slightly granular, eosinophilic cytoplasm and a prominent, round nucleus with coarse chromatin and centrally placed nucleoli (B - surgery 2011). MIB-1 labelling index with a focal increase in proliferation activity (C - surgery 2005, D - surgery 2011). Bars: $A, B, C, D-50 \mu m$.

the null cell type. Because of invasive growth, high MIB-1 labelling index and metastases, the primary pituitary carcinoma was considered. Further evaluation of immunohistochemical staining revealed strong immunoreactivity for cytokeratin (AE1/AE3), thyroglobulin, S-100 and TTF1 (Figs. 3B-D). Such immunohistochemical profile correlated with the clinical history allowed us to establish the warrant diagnosis of pituitary metastases of the oncocytic variant of follicular thyroid carcinoma.

\section{Discussion}

The majority of metastatic tumours localized in the pituitary gland are asymptomatic, thus usually discovered incidentally. Data derived from autopsies indicate that metastases to the pituitary gland ranged from $3.0 \%$ up to $27 \%$ in patients with systemic malignancies $[28,36]$. Only $1-7 \%$ of surgically excised neoplastic metastases to the pituitary gland have been associated with distinct clinical symptoms [18,23]. The clinical presentation and radiological picture of pituitary metastases are usually typical of primary non-functioning pituitary adenoma and the preoperative diagnosis is often misleading [11,29,31,37,41]. The clinical features in symptomatic patients with pituitary metastases include: diabetes insipidus alone or with signs of anterior pituitary insufficiency, visual field alterations, ophthalmoplegia and general symptoms i.e. weakness or anaemia, secondary to hypopituitarism $[1,18,23,31,38]$. Only a few symptoms, including diabetes insipidus, ophthalmoplegia or ptosis are not typical of primary pituitary adenoma and 

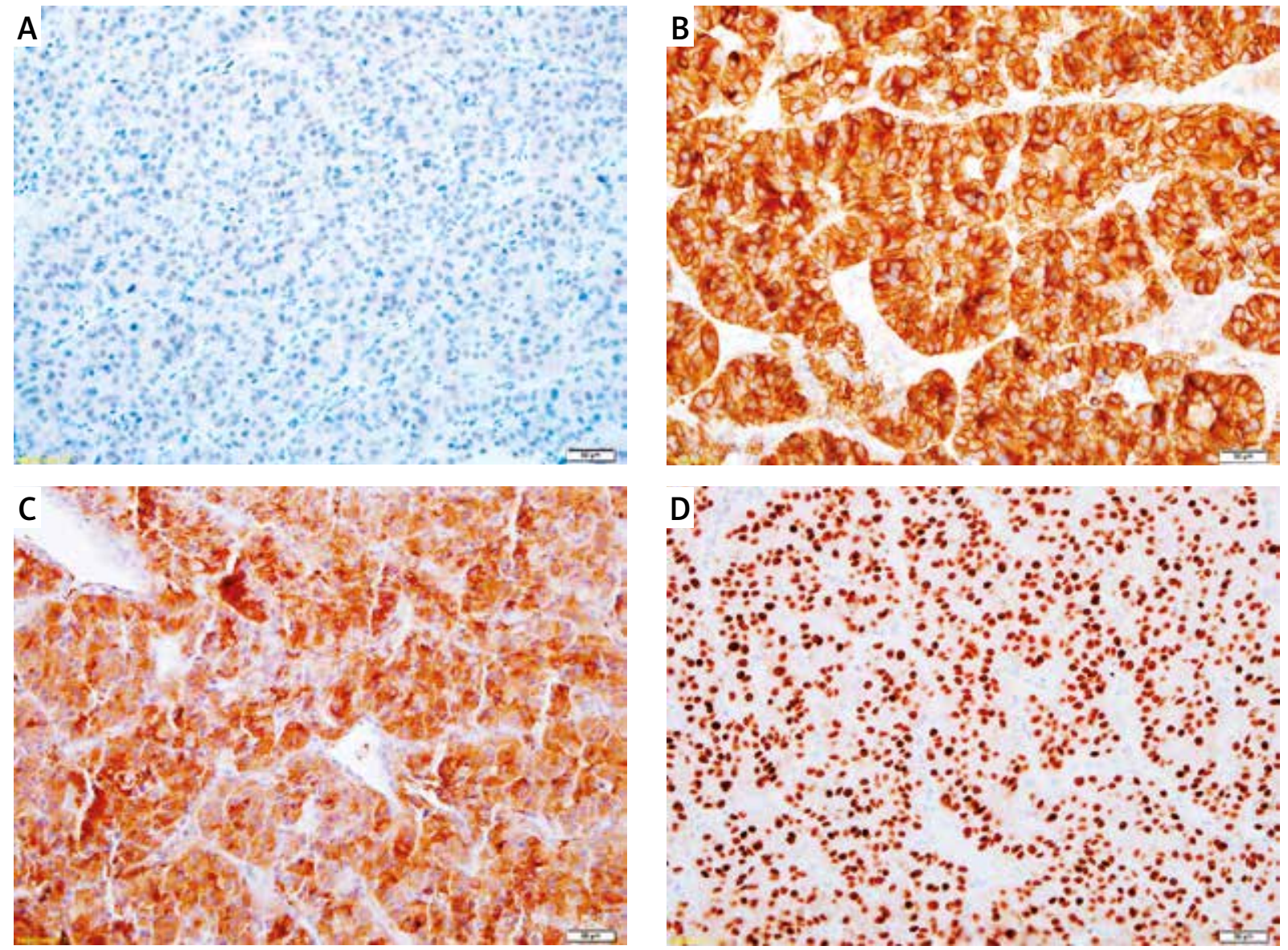

Fig. 3. Immunohistochemistry. The neoplastic cells immunonegative for synaptophysin (A). The strong immunoreactivity of neoplastic cells for AE1/AE3 (B), thyroglobulin (C) and TTF1 (D). Bars: A, B, C, D - $50 \mu \mathrm{m}$.

indicate rather secondary metastatic origin [22]. MR imaging and histopathological picture of metastases might indicate the pituitary adenoma. Also the molecular results are not a great help in differential diagnosis as molecular etiopathogenesis of pituitary adenomas still remains largely unknown, although some differences in gene expression between functional and non-functional adenomas have been detected $[24,25]$. Often, precise immunohistochemical and electron microscopic studies are necessary to establish an accurate diagnosis.

Surgical treatment of pituitary tumours with advanced tumour growth and invasion of adjacent structures is usually limited to diagnostic biopsy or subtotal resection. Surgery or local radiotherapy might reduce the severity of neurological symptoms resulting from pituitary localization of metastatic tumour, i.e. improved visual field, correction of impaired eye movement
$[19,22,46]$. However, the symptoms of hypopituitarism and diabetes insipidus are usually irreversible.

Metastases of endocrine tumours to the neuroendocrine part of the pituitary gland can be related with significant diagnostic difficulties [20]. Most commonly the metastases affect the posterior pituitary lobe with a rich arterial supply [28]. The pituitary metastases can originate from various primary sites but most often from the breast and lung $[18,23]$. Intracranial metastases from thyroid carcinoma involving the sellar region and pituitary gland are very rare $[4,5,8]$. Most reported cases of pituitary thyroid metastases have originated from papillary and follicular thyroid carcinoma that comprise about $90 \%$ of thyroid cancers $[13,14]$. The correlation between metastases and size of primary thyroid tumor and vascular invasion have been suggested [17]. Only a few cases of pituitary metastases from medullary carcinoma of the thyroid have been reported $[9,10,15,44]$. Follicular 


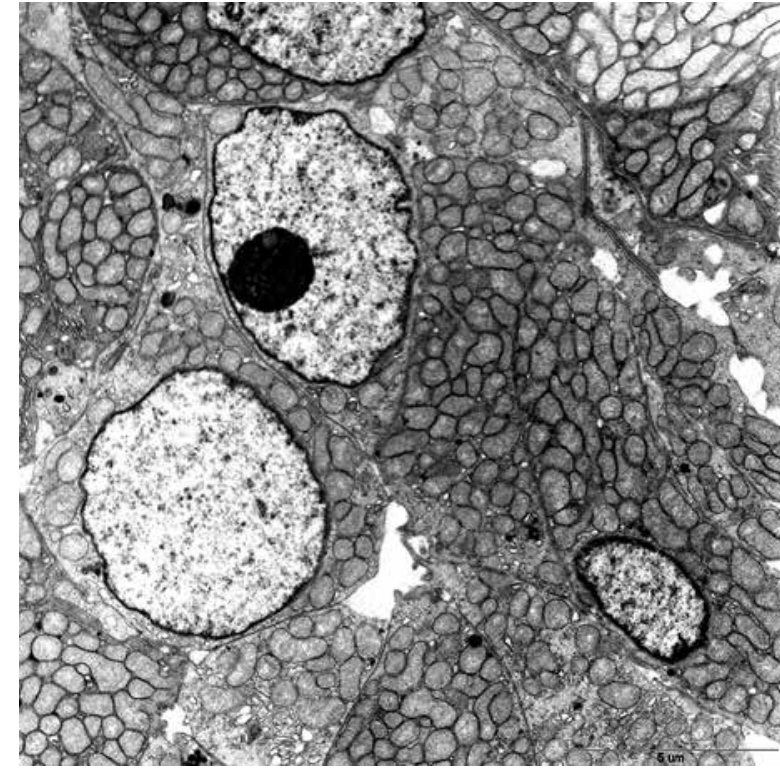

Fig. 4. The cytoplasm of neoplastic cells filled with numerous mitochondria.

variant of papillary thyroid carcinoma (FVPTC) is the most common type of papillary thyroid carcinoma (PTC) $[33,35,40,43,45]$. The oncocytic variants of papillary and follicular carcinoma of the thyroid are very uncommon and especially the biology of the last one is more aggressive and commonly displays lymph node metastasis [7,12,39].

In the present case, the final correct diagnosis was established after correlation with clinical data. Initially both immunohistochemical and ultrastructural features might suggest an atypical, non-functioning, hormone-negative, null cell pituitary adenoma oncocytic type or invasive primary pituitary carcinoma. However, the oncocytic features in pituitary tumours require prompt consideration of oncocytic variants of different metastatic tumours. It is important to differentiate the oncocytic type of pituitary adenoma and secondary tumours with oncocytic features because of their differences in medical treatment and clinical outcome.

Oncocytic changes are highly characteristic on conventional hematoxylin and eosin staining. They are characterized by abundant eosinophilic, granular cytoplasm, distinct cell borders and large hyperchromatic nuclei with prominent nucleoli. They have been described in various organs of the neuroendocrine system including the thyroid, parathyroid, adrenal cortex, pancreas and outside the endocrine system in salivary glands and renal $[2,3]$. However,

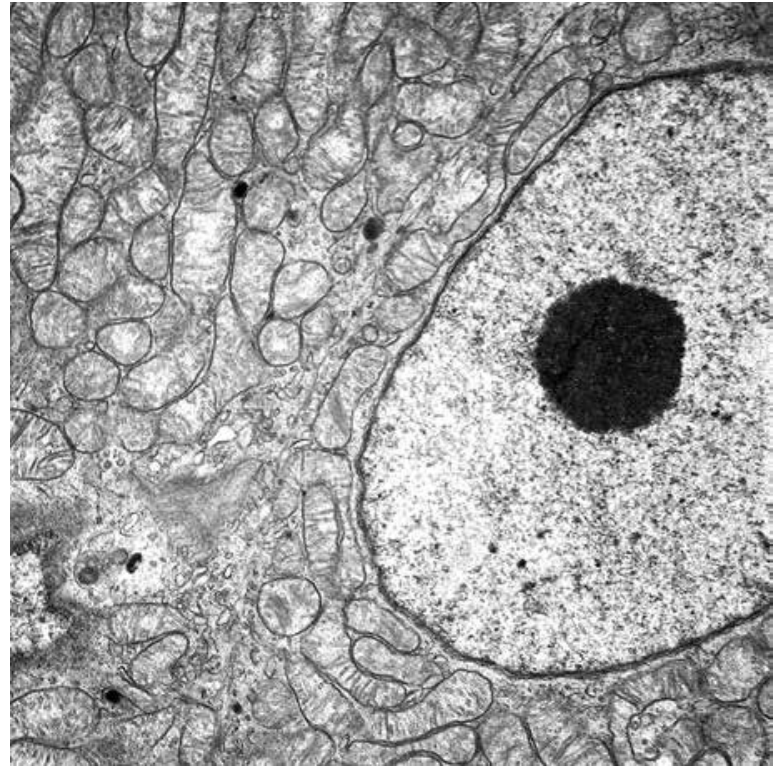

Fig. 5. Fragments of oncocytic cytoplasm with abundance of mitochondria of various shape and swollen matrix with flattened cristae. The nucleus exhibits uniformly dispersed chromatin and a prominent nucleolus.

oncocytic tumours ought to be diagnosed with caution because of high background or non specific immunostaining.

Oncocytic cells of the thyroid was first described by Askanazy but are also known as Hürthle or oxyphilic cells [30]. The true oncocytic cells are derived from follicular cells, whereas Hürthle described parafollicular calcitonin-producing cells. Oncocytic tumours composed predominantly or exclusively of oncocytic cells are rare. In the thyroid, oncocytic neoplastic lesions include spindle cell oncocytoma of adenohypophysis [27]. Follicular thyroid carcinoma might be also composed of large, polygonal, oncocytic cells [2]. The oncocytic/Hürthle cell thyroid carcinoma demonstrates a more aggressive clinical behaviour than non-Hürthle cell follicular carcinoma. In electron microscopy images, the granularity of enlarged cytoplasm of oncocytic cells results from accumulation of abnormal mitochondria that are evenly distributed throughout the cytoplasm [42]. Ghadially et al. [21] proposed that cells with abundance of mitochondria that fill $60 \%$ of the total cytoplasm might be identified as true oncocytes.

In the present case, the correlation of immunohistochemical staining with a clinical history of primary thyroid cancer allowed us to establish the war- 
rant diagnosis of the oncocytic variant of follicular thyroid carcinoma. The neoplastic cells occurred to be immunoreactive for cytokeratin AE1/AE3, thyroglobulin and thyroid transcription factor 1 (TTF-1) and negative for pituitary hormones. Positivity for thyroglobulin and TTF-1 confirmed the diagnosis of thyroid carcinoma.

Concluding, the differential diagnosis of invasive parasellar tumours that lack pituitary hormone immunoreactivity is especially challenging and includes silent, non-functional pituitary adenoma or metastatic carcinomas. The wide immunohistochemical profile and electron microscopic studies might help to establish the correct diagnosis in metastatic pituitary cases. The oncocytic variant of follicular thyroid carcinoma, although very rare, should be considered in the differential diagnosis of sellar-region mass lesions of oncocytic morphology.

The studies were partly supported by the grant of Military Institute of Medicine No 1/8807(258)/2013.

\section{References}

1. Ariel D, Sung H, Coghlan N, Dodd R, Gibbs IC, Katznelson L. Clinical Characteristics and Pituitary Dysfunction in Patients with Metastatic Cancer to the Sella. Endocr Pract 2013; 11: 1-16.

2. Asa SL. My approach to oncocytic tumours of the thyroid. J Clin Pathol 2004; 57: 225-232.

3. Baloch ZW, LiVolsi VA. Oncocytic lesions of the neuroendocrine system. Semin Diagn Pathol 1999; 16: 190-199.

4. Barbaro D, Desogus N, Boni G. Pituitary metastasis of thyroid cancer. Endocrine 2012; 43: 485-493.

5. Bell CD, Kovacs K, Horvath E, Smythe H, Asa S. Papillary carcinoma of thyroid metastatic to the pituitary gland. Arch Pathol Lab Med 2001; 125: 935-938.

6. Benjamin L. Ein Krebsfall. Virchows Arch Pathol Anat 1857; 12: 566-569.

7. Berho M, Suster S. The oncocytic variant of papillary carcinoma of the thyroid: a clinicopathologic study of 15 cases. Hum Pathol 1997; 28: 47-53.

8. Besic N, Gazic B. Sites of metastases of anaplastic thyroid carcinoma: autopsy findings in 45 cases from a single institution. Thyroid 2013; 23: 709-713.

9. Bhatoe HS, Badwal S, Dutta V, Kannan N. Pituitary metastasis from medullary carcinoma of thyroid: case report and review of literature. J Neurooncol 2008; 89: 63-67.

10. Bobinski M, Greco CM, Schrot RJ. Giant intracranial medullary thyroid carcinoma metastasis presenting as apoplexy. Skull Base 2009; 19: 359-362.

11. Branch CL, Jr., Laws ER, Jr. Metastatic tumors of the sella turcica masquerading as primary pituitary tumors. I Clin Endocrinol Metab 1987; 65: 469-474.
12. Carcangiu ML, Bianchi S, Savino D, Voynick IM, Rosai J. Follicular Hurthle cell tumors of the thyroid gland. Cancer 1991; 68: 1944-1953.

13. Chhiber SS, Bhat AR, Khan SH, Wani MA, Ramzan AU, Kirmani AR, Malik NK, Wani AA, Rather T. Apoplexy in sellar metastasis: a case report and review of literature. Turk Neurosurg 2011; 21: $230-234$

14. Chrisoulidou A, Pazaitou-Panayiotou K, Flaris N, Drimonitis A, Giavroglou I, Ginikopoulou E, Vainas I. Pituitary metastasis of follicular thyroid carcinoma. Horm Res 2004; 61: 190-192.

15. Conway A, Wiernik A, Rawal A, Lam C, Mesa H. Occult primary medullary thyroid carcinoma presenting with pituitary and parotid metastases: case report and review of the literature. Endocr Pathol 2012; 23: 115-122.

16. de la Monte SM, Hutchins GM, Moore GW. Endocrine organ metastases from breast carcinoma. Am J Pathol 1984; 114: 131-136.

17. Ece H, Devrim CD, Pelin TA, Ahmet G, Ozgur NM, Mustafa H, Mithat B. Clinical experience of thyroid carcinoma: a study of 178 cases. Contemp Oncol (Pozn) 2012; 16: 218-222.

18. Fassett DR, Couldwell WT. Metastases to the pituitary gland. Neurosurg Focus 2004; 16: E8.

19. Feiz-Erfan I, Rao G, White WL, McCutcheon IE. Efficacy of Transseptal Trans-sphenoidal Surgery in Correcting Visual Symptoms Caused by Hematogenous Metastases to the Sella and Pituitary Gland. Skull Base 2008; 18: 77-84.

20. Freda PU, Post KD. Differential diagnosis of sellar masses. Endocrinol Metab Clin North Am 1999; 28: 81-117, vi.

21. Ghadially FN, Block HJ. Oncocytic carcinoid of the lung. I Submicrosc Cytol 1985; 17: 435-442.

22. Kattah JC, Silgals RM, Manz H, Toro JG, Dritschilo A, Smith FP. Presentation and management of parasellar and suprasellar metastatic mass lesions. J Neurol Neurosurg Psychiatry 1985; 48: 44-49.

23. Komninos J, Vlassopoulou V, Protopapa D, Korfias S, Kontogeorgos G, Sakas DE, Thalassinos NC. Tumors metastatic to the pituitary gland: case report and literature review. J Clin Endocrinol Metab 2004; 89: 574-580.

24. Larysz D, Blamek S, Rudnik A. Clinical aspects of molecular biology of pituitary adenomas. Folia Neuropathol 2012; 50: 110-117.

25. Larysz D, Zebracka-Gala J, Rudnik A, Hasse-Lazar K, Kowalska M, Jarzab M, Krol A, Szpak-Ulczok S, Bazowski P, Jarzab B. Expression of genes FOLR1, BAG1 and LAPTM4B in functioning and non-functioning pituitary adenomas. Folia Neuropathol 2012; 50: $277-286$

26. Leaes CG, Silva LA, Pereira-Lima JF, Kramer J, Oliveira Mda C. Pituitary metastasis from adenocarcinoma. Arq Neuropsiquiatr 2011; 69: 845-846.

27. Matyja E, Maksymowicz M, Grajkowska W, Olszewski W, Zielinski G, Bonicki W. Spindle cell oncocytoma of the adenohypophysis - a clinicopathological and ultrastructural study of two cases. Folia Neuropathol 2010; 48: 175-184.

28. Max MB, Deck MD, Rottenberg DA. Pituitary metastasis: incidence in cancer patients and clinical differentiation from pituitary adenoma. Neurology 1981; 31: 998-1002.

29. McCormick PC, Post KD, Kandji AD, Hays AP. Metastatic carcinoma to the pituitary gland. Br J Neurosurg 1989; 3: 71-79. 
30. Mete O, Asa SL. Oncocytes, oxyphils, Hurthle, and Askanazy cells: morphological and molecular features of oncocytic thyroid nodules. Endocr Pathol 2010; 21: 16-24.

31. Morita A, Meyer FB, Laws ER, Jr. Symptomatic pituitary metastases. J Neurosurg 1998; 89: 69-73.

32. Moshkin O, Rotondo F, Scheithauer BW, Soares M, Coire C, Smyth HS, Goth M, Horvath E, Kovacs K. Bronchial carcinoid tumors metastatic to the sella turcica and review of the literature. Pituitary 2012; 15: 160-165.

33. Ozdemir D, Ersoy R, Cuhaci N, Arpaci D, Ersoy EP, Korukluoglu B, Guler G, Cakir B. Classical and follicular variant papillary thyroid carcinoma: comparison of clinical, ultrasonographical, cytological, and histopathological features in 444 patients. Endocr Pathol 2011; 22: 58-65.

34. Pozzessere D, Zafarana E, Buccoliero AM, Pratesi C, Fargnoli R, Di Leo A. Gastric cancer metastatic to the pituitary gland: a case report. Tumori 2007; 93: 217-219.

35. Prodam F, Pagano L, Belcastro S, Golisano G, Busti A, Sama M, Caputo M, Bellone S, Voci A, Valente G, Aimaretti G. Pituitary metastases from follicular thyroid carcinoma. Thyroid 2010; 20: 823-830.

36. Roessmann U, Kaufman B, Friede RL. Metastatic lesions in the sella turcica and pituitary gland. Cancer 1970; 25: 478-480.

37. Ruelle A, Palladino M, Andrioli GC. Pituitary metastases as pre senting lesions of malignancy. J Neurosurg Sci 1992; 36: 51-54.

38. Santarpia L, Gagel RF, Sherman SI, Sarlis NJ, Evans DB, Hoff AO. Diabetes insipidus and panhypopituitarism due to intrasellar metastasis from medullary thyroid cancer. Head Neck 2009; 31: 419-423.

39. Schmid KW, Farid NR. How to define follicular thyroid carcinoma? Virchows Arch 2006; 448: 385-393.

40. Simon N, Quyyumi SA, Rothman JG. Follicular thyroid cancer presenting as a sellar mass: case report and review of the literature. Endocr Pract 2004; 10: 62-66.

41. Sioutos P, Yen V, Arbit E. Pituitary gland metastases. Ann Surg Oncol 1996; 3: 94-99.

42. Sobrinho-Simoes MA, Nesland JM, Holm R, Sambade MC Johannessen JV. Hurthle cell and mitochondrion-rich papillary carcinomas of the thyroid gland: an ultrastructural and immunocytochemical study. Ultrastruct Pathol 1985; 8: 131-142.

43. Vianello F, Mazzarotto R, Taccaliti A, Lora O, Basso M, Servodio O, Mian C, Sotti G. Follicular thyroid carcinoma with metastases to the pituitary causing pituitary insufficiency. Thyroid 2011; 21: 921-925.

44. Williams MD, Asa SL, Fuller GN. Medullary thyroid carcinoma metastatic to the pituitary gland: an unusual site of metastasis. Ann Diagn Pathol 2008; 12: 199-203.

45. Yilmazlar S, Kocaeli H, Cordan T. Sella turcica metastasis from follicular carcinoma of thyroid. Neurol Res 2004; 26: 74-78.

46. Zoli M, Mazzatenta D, Faustini-Fustini M, Pasquini E, Frank G. Pituitary metastases: role of surgery. World Neurosurg 79: 327-330. 